\title{
Escritura, encarnação, temporização: Merleau-Ponty e Derrida acerca de A origem da Geometria
}

\author{
Emmanuel Alloa \\ emmanuel.alloa@unisg.ch \\ Professor Assistente University of St. Gallen, St. Gallen, Suiça
}

resumo A história intelectual do século XX tem sido escrita ao longo de um cenário que vê, na morte de Merleau-Ponty em 1961, a linha de divisória entre uma geração existencial e fenomenológica e o evento do estruturalismo imediatamente subsequente. A publicação das notas de leitura de Merleau-Ponty sobre o texto $A$ origem da geometria, de Edmund Husserl, tem mostrado quão frágeis são os alicerces desta leitura simplificadora. Na verdade, enquanto a tradução e introdução de Derrida ao texto de Husserl, de 1962, tornavam-se um texto fundamentador para a geração estruturalista, introduzindo uma reflexão sobre a historicidade e a materialidade da idealidade, foi apenas em 1998, com a publicação das notas da conferência de Merleau-Ponty no Collège de France, em 1959, sobre o mesmo tópico, que se tornou claro quão próximo está o primeiro Derrida do último Merleau-Ponty. Assim como Derrida, Merleau-Ponty identificou, na tensão husserliana entre arqueologia e teleologia, o problema básico da fenomenologia, introduzindo a questão da história e a do meio de transmissão cultural. Comparar tais leituras em seu contexto específico não apenas permite um retrato mais complexo dos debates intelectuais da época, mas também mostra como, com a interpretação de Merleau-Ponty sobre $A$ origem da geometria, a "diferença" de Derrida antecede-se e admite outra genealogia.

palavras-chaves idealidade; história; mediador; escritura; origem; diferença

\section{1961: Ruptura ou continuidade?}

A ideia que uma década intelectual pôde constituir de si mesma, em reação àquela que a precedeu, acabou por se tornar uma idéia feita, uma 
idéia recebida e retomada sem sombras de suspeita pela história intelectual do séc. XX: tal é a ideia de que os anos 60 teriam marcado o fim de um pensamento da existência em benefício de um triunfo das estruturas, a substituição de uma filosofia do sujeito por um conceito de sentido difratado. $\mathrm{O}$ destino do estruturalismo e aquele de sua fortuna estariam imediatamente ligados ao brusco declínio do existencialismo, e a desaparição de Merleau-Ponty, em 1961, marcaria um ponto sem retorno de um movimento que apenas se subordina às necessidades da história. O que alguns quiseram interpretar como uma mudança de paradigma, ao refazer as circunstâncias históricas de seu acontecimento, Michel Foucault propôs explicar em duas posturas respectivas, referentes ao que está em jogo no lógos. Ao opor às "filosofias do conceito" as "filosofias do sujeito", que representam o existencialismo e a fenomenologia, há, segundo Foucault, toda distância entre um pensamento que confia nas potências da idealização e outro que identifica exatamente estas últimas como a causa da crise. A alusão é mal dissimulada, uma vez que Foucault, em $A$ ordem do discurso, faz referência a essa "profunda logofobia" que caracterizaria o pensamento contemporâneo, esse medo "contra o grande zumbido incessante e desordenado do discurso" (FOUCAULT 1971, p.51).

No que originalmente era um prefácio à edição americana do livro de Canguilhem, O normal e o patológico, Foucault distingue duas abordagens da vida, uma ligada ao mundo vivido e outra à ciência, dando lugar à clivagem que separa "uma filosofia da experiência, do sentido, do sujeito, e uma filosofia do saber, da racionalidade e do conceito" (FOUCAULT 1985 republicado em FOUCAULT 2001). No entanto, se, em $A$ ordem do discurso, a fenomenologia é constrangida a desempenhar o papel de filosofia logofóbica, impedindo, por seu subjetivismo, toda confrontação séria com as formas anônimas do discurso, Foucault revela-se bem menos incisivo em outros textos. A oposição entre filosofia subjetiva e filosofia do discurso não se opera mais entre a fenomenologia e a sua substituição, desde os anos 60, pelo estruturalismo, mas se torna mais complexa e confusa, uma vez que ela se decide, se olharmos bem, dentro da própria fenomenologia husserliana. O que se apresenta como um abandono da via fenomenológica seria melhor compreendido como um reforço de seu aspecto subjetivo que, se não apareceu na filosofia clássica, não deixou de 
atrair a atenção da filosofia das ciências. Foucault lembra que as Meditações cartesianas de Hussserl foram, desde cedo,

a disputa de duas leituras possíveis: a primeira, na direção de uma filosofia do sujeito, que procurava radicalizar Husserl, e não demoraria encontrar as questões que Heidegger se coloca em Ser e tempo, é o artigo sobre a Transcendência do ego, em 1935; a segunda, aquela do formalismo e do intuicionismo, que remonta aos problemas fundadores do pensamento de Husserl, ocorre em 1938, com as duas teses de Cavallès sobre o Método axiomático e a Formação da teoria dos conjuntos. (Idem, ibidem.)

É toda essa filiação, de Cavallès a Canguilhem, passando por Koyré e Bachelard, que dá aparência de autoridade, segundo Foucault, para uma reflexão renovada, tanto das condições históricas da objetivação quanto das condições de emergência da significação - da qual teria se desviado uma das duas filiações, identificada por Foucault com a posição de Sartre, mas também Merleau-Ponty. "Pertenço a uma geração de pessoas para as quais o horizonte da reflexão foi definido por Husserl de uma maneira geral, mais precisamente por Sartre, mais precisamente ainda por Merleau-Ponty. E é evidente que, pelos anos 55, [...] este horizonte caiu por terra para nós." (FOUCAULT 2001a, p.695).

Jacques Derrida se pronunciou de modo análogo, ao explicar porque seus primeiros trabalhos são mais sensíveis à questão da idealidade de Husserl, e não outro tema, mais recorrente, que é a subjetividade: "A preocupação que eu partilhava com muita gente na época", ele explica numa entrevista, "era a de substituir uma fenomenologia à francesa (Merleau-Ponty e Sartre), pouco preocupada com a cientificidade e com a epistemologia, por uma fenomenologia mais voltada às ciências" (JANICAUD 2001, p.93). A recepção da fenomenologia, explica ainda, era feita através de um "dispositivo estranho e anterior à questão da ciência, isto é, através da fenomenologia da percepção, da antropologia e da ontologia sartriana; todavia, no fundo, ainda não se havia acertado as contas com os problemas da epistemologia, as reflexões sobre a história das ciências, a idealidade das matemáticas" (FERRARIS 1997, p.40). Ou, como ele pode dizer na ocasião de sua defesa acadêmica de tese, em 1980: trat-se de praticar uma fenome- 
nologia "contra ou sem as versões sartriana e merleau-pontyana, que dominavam" (DERRIDA 1990a, p.444).

Poderíamos prosseguir aqui estas referências, tanto em Foucault quanto em Derrida, a partir de inumeráveis textos e entrevistas. Mas o que aí se confirmaria já se anuncia nestas poucas citações. Quando Foucault e Derrida fazem remontar a gênese de um pensamento estrutural à filosofia das idealidades de Husserl, ambos o fazem apontando o dedo para uma tradição que faria obstáculo à compreensão: esta de Sartre e MerleauPonty. Singularmente - e só podemos assinalar - esses dois nomes são citados juntos, como se formassem uma unidade indissociável, responsável pela negação da ciência e rejeição do discursivo.

Constatação esta que é tanto mais surpreendente quando se compara à narrativa que Derrida faz de seus anos de formação: recebido na École Normale Supérieure em 1952, acompanhou as lições do professor titular em psicologia, Michel Foucault, cujos cursos versavam precisamente sobre "Merleau-Ponty e as Ideen II" e "Merleau-Ponty e a afasia; Goldstein e a patologia" (Idem, p.41). Lições que, segundo Derrida, desempenhavam um papel maior na forma como tomou interesse pela fenomenologia, e que, no seu entrelaçamento natural da filosofia com as ciências empíricas, vêm corrigir a imagem de uma fenomenologia merleaupontyana hostil às ciências (Idem, ibidem). Ora, não é somente Foucault que se revela bem mais influenciado pela fenomenologia merleaupontyana do que o admitiria publicamente $\neg$ (não falta a nenhuma das aulas de Merleau-Ponty na École Normale Supérieure, em 1947/8 e em 1948/9, ainda que oficialmente versassem sobre Malebranche, Maine de Biran, Bergson e as relações entre corpo e alma, tocavam também, como lembra Didier Eribon, a questão da linguagem (ERIBON 1989, p.49), Derrida é também fortemente influenciado pelo pensamento merleaupontyano, bem mais do que algumas referências, raríssimas, encontradas na sua obra, dão a entender.

Sem dúvida, o mais singular dos fatos é que o ângulo de ataque escolhido por Derrida para se afastar dessa "fenomenologia à francesa (Sartre, Merleau-Ponty)", tão pouco preocupada com as idealidades objetivas, seja aquele de $A$ origem da geometria de Husserl, que traduzirá e comentará em 1962, ou seja, exatamente o texto de Husserl que Merleau-Ponty havia se encarregado de comentar, com uma atenção que não dedicou a 
nenhum outro texto husserliano, na ocasião de seu curso no Collège de France, em 1959, marcando mais de um ouvinte, filósofo ou não ${ }^{1}$.

No que segue, tratar-se-á de embaralhar mais uma vez as cartas para redistribuí-las de outra maneira, mostrando a proximidade perturbadora entre o último Merleau-Ponty e o primeiro Derrida. Mais de uma vez, as leituras respectivas de $A$ origem da geometria parecem inverter-se perigosamente, quando Derrida insistirá sobre a necessidade da encarnação e Merleau-Ponty sobre a da escrita, a tal ponto que o quiasma que se amarra aqui, num momento crucial para o pensamento contemporâneo dos 60, produz uma indistinção que coloca em questão a cartografia herdada e suas linhas divisórias tão claras.

\section{A outra origem}

Antes de poder melhor compreender a querela filosófica disto que Leonard Lawlor qualificava corretamente de perturbadora "continuidade" entre Merleau-Ponty e Derrida (LAWLOR 2000, p.337), é preciso relembrar brevemente o contexto histórico que confirma esta ideia. Com efeito, o ano de 1961 parece marcar uma reviravolta de primeira grandeza. Derrida acaba a tradução de $A$ origem da geometria em julho, ou seja, logo após a morte de Merleau-Ponty, em maio. A tradução render-lhe-á imediatamente o reconhecimento entre os filósofos da ciência e o prestigioso Prêmio Cavaillès, recebido ainda naquele mesmo ano. Com a publicação da tradução no ano seguinte, em outono de 1962, acompanhada de uma introdução três vezes mais volumosa do que o texto de que constitui o comentário, a transição entre a geração existencialista e a geração estruturalista parece estar terminada.

Ora, nada é menos certo do que poder identificar Derrida ao estruturalismo e Merleau-Ponty a uma filosofia existencialista que seria alérgica às ciências empíricas. Em trabalho recente apoiado sobe numerosas notas inéditas, Edward Baring pôde mostrar que o primeiro Derrida só se engaja no debate com o estruturalismo por volta de meados dos anos 60 , e que as leituras de Heidegger ou as do existencialismo cristão são preponderantes ao longo de seus primeiros anos de formação ${ }^{2}$. Inversamente, Merleau-Ponty é talvez um dos primeiros filósofos a avaliar a 
importância da questão estruturalista nas ciências humanas, notadamente graças a relação privilegiada com Claude Lévi-Strauss e Jacques Lacan, de quem era amigo. Desde a publicação, em 1998, das notas preparatórias de Merleau-Ponty para o curso sobre $A$ origem da geometria, ministrado em 1959/60, no Collège de France, a imagem de uma ruptura de gerações não se sustenta, dando lugar a uma imagem mais complexa e rica do "momento filosófico" que faz o entorno do desaparecimento de Merleau-Ponty ${ }^{3}$.

Doravante pode-se dizer, como o faz Etienne Balibar, que Derrida toma "algo como o lugar" (BALIBAR 2002, p.503) de Merleau-Ponty? Sim e não, pois efetivamente Derrida não esperou o curso de MerleauPonty para se interessar pelo apêndice IV da Krisis de Husserl, sobre $A$ origem da geometria. Se Merleau-Ponty foi o primeiro pesquisador estrangeiro a visitar os Arquivos Husserl de Louvain, em 1939, numa visita que foi decisiva para toda a história da recepção da fenomenologia alemã na França, Derrida aí também se detém desde muito cedo, por ocasião de sua dissertação sobre o Problema da gênese na filosofia de Husserl, redigida sob a orientação de Maurice de Gandillac. Graças ao intermédio deste último, Derrida pôde se encontrar com o padre Van Breda, responsável pela transferência dos Nachlass de Husserl a Louvain e fundador dos Arquivos, além de passar quinze dias no país, para consultar os manuscritos $^{4}$. A publicação, em 1990, dessa dissertação permite medir ao mesmo tempo o rigor e a perspicácia desta primeira interpretação que Derrida propõe de Husserl. Ele não apenas é o primeiro, sem dúvida, na França, a conceder importância ao jovem Husserl da Filosofia da aritmética, mas também aquele a mostrar como a preocupação do enraizamento mundano das idealidades continua, e mesmo se radicaliza, ao longo de toda a sua obra. A importância do anexo IV estará desde então identificada: "Ao fim de sua vida, Husserl, em $A$ origem da geometria, tentará mais uma vez uma re-atualização (Reaktivierung) do sentido originário da operação ou da produção (Leistung) matemática (DERRIDA 1990, p.57).

Em certo sentido, se a fenomenologia husserliana acaba inegavelmente sobre uma filosofia do ego transcendental, Husserl permanece sempre consciente de que a verdadeira dificuldade não está em reformular uma nova filosofia transcendental, mas de explicar os estratos que - numa perspectiva rigorosamente fenomenológica - não podem resultar de uma 
simples dedução lógica. O problema das idealidades, e portanto de qualquer coisa que é válida através de todas as suas variações empíricas, é então um problema que não é lógico, mas genético, no sentido de que a própria lógica deve ser compreendida como resultado de uma gênese. "Uma unidade de intenção liga então a Filosofia da aritmética e $A$ origem da geometria, atravessando todos os seus momentos intermediários", escreve ainda Derrida, acrescentando que antes de chegar à "gênese transcendental, Husserl teve de partir, sem embargo, de uma gênese empírica". Este ponto de partida empírico deve comprometer definitivamente toda esperança de encontrar uma esfera puramente transcendental: "É duvidoso, prossegue Derrida, que a gênese empírica nos faça tocar os estratos absolutos das matemáticas e da filosofia"5.

Derrida, que, como Merleau-Ponty, interessa-se muito cedo pelo problema da psicologia do desenvolvimento, e que apresentou uma aula expositiva, em 1954 ou 1955, onde o problema da gênese em Jean Piaget desempenha um papel maior 6 , rejeita, ao lado de Husserl, toda psicologização da questão genética: postular alguma coisa como uma origem psicológica do desenvolvimento do indivíduo reconduziria a repetir, dessa vez sobre o aspecto histórico-empírico, a ilusão de uma origem primeira e absoluta visada por toda metafisica. Em virtude de sua ancoragem metodológica no vivido, aceitada como única "fonte" de conhecimento verdadeiro, a fenomenologia husserliana deve decepcionar de cara toda pretensão absoluta de um fundamento primeiro, de uma origem autônoma e separável. E, no entanto, a questão da origem absoluta obseda todo o pensamento husserliano, pois ela não se deixa reduzir a uma gênese mundana, a uma explicação causal e, por isso, inevitavelmente externalista. Eis aí toda a tensão interna ao projeto husserliano, identificada por Derrida perfeitamente desde 1954, e que impõe à fenomenologia uma dupla obrigação: "a exigência de um começo absoluto, de um lado, e a temporalidade do vivido como referência filosófica última, de outro"; uma filosofia que, desde então, "a um só tempo reivindica para a filosofia um novo rigor científico e a reenvia à pureza do vivido concreto" (DERRIDA 1990b, p.3). Mas como conciliar o intuicionismo e a temporalização, como explicar que uma intuição - cujo caráter intuitivo não pode ser senão obrigatoriamente temporário - persista no tempo? Segundo Derrida, é numa passagem tão breve quanto obscura de $A$ 


\section{8}

origem da geometria, este pequeno texto de 1936, que Husserl tocaria na solução: não há persistência de uma idealidade intuída senão onde ela é sedimentada por uma inscrição material, o que equivale a dizer que a questão da intuição se conduz diretamente para a escrita.

Em uma entrevista de 1998, Derrida recorre novamente a essa descoberta:

Imediatamente após a licenciatura [1956], eu me lembro de ter

procurado Jean Hippolyte e lhe ter dito: "Eu quero traduzir $A$ origem da geometria e trabalhar sobre este texto." A razão é que havia uma nota breve e elíptica sobre a escrita, sobre a necessidade para a comunidade científica de constituir objetos ideais comunicáveis a partir de intuições do objeto matemático. Husserl dizia que somente a escrita poderia dar a estes objetos ideais sua idealidade final, que só ela permitir-lhes-ia entrar na história de algum modo, enfim, que sua historicidade viria da escrita. $^{7}$

No segunda metade de 1956 e primeira de 1957, quando se beneficia de uma temporada de estudos na Universidade de Harvard na qualidade de aluno especial, Derrida trabalha com os microfilmes da obra póstuma de Husserl e começa a traduzir $A$ origem da geometria. No mesmo período, Jean Hippolyte, então diretor da École Normale Supérieure, tenta , com Merleau-Ponty, depois de duas tentativas sem sucesso, em 1942 e 1946, mais uma vez criar um setor permanente para os textos de Husserl em Paris. Algo que se concretizará, finalmente, por ocasião do colóquio Husserl realizado em Royaumont, em abril de 1957, quando um acordo é firmado entre o padre Van Breda e as instituições parisienses. No ano seguinte, em maio de 1958, um Centro Husserl é oficialmente inaugurado na Biblioteca da Sorbonne. Durante esta época, Derrida está na Algéria, onde presta o serviço militar como civil, ensinando crianças das forças armadas. Retornando da Algéria em 1959, fará sua primeira conferência pública em Cerisy-la-Salle sobre a "Gênese e Estrutura da Fenomenologia", sem abandonar o trabalho de tradução da Beilage da Krisis. Merleau-Ponty, que projetava uma tradução francesa da Krisis, publicada depois na coleção "Biblioteca de Filosofia", dirigida por ele e Sartre ${ }^{8}$, contacta Derrida pelo correio, propondo-lhe o empreendimento de tradução completa da Krisis. Muitas cartas são trocadas e o projeto 
permanecerá onde está, abandonado em seguida pela morte repentina de Merleau-Ponty ${ }^{9}$. Derrida publica, em 1962, somente a edição comentada da Beilage III.

\section{A sombra de um pensamento}

Além da narrativa da recepção francesa de um fragmento de Husserl, onde se entrelaçam de modo particular os percursos intelectuais de Merleau-Ponty e Derrida, é preciso perguntar pelo que chama a atenção de ambos os filósofos neste escrito que, tanto por seu propósito quanto por seu caráter de "acessório", inserido no texto principal da Krisis, à primeira vista parece tão marginal. Como explicar que em 1959/60, durante o seu curso às segundas no Collège de France, Merleau-Ponty se aplica minuciosamente ao comentário deste texto, enquanto que outras traduções de textos maiores já eram disponíveis em francês, como por exemplo a tradução de Emmanuel Levinas das Meditações Cartesianas (1931) e a tradução de Paul Ricoeur das Ideen (1950)? Como justificar essa aproximação lateral e indireta com a obra de Husserl, passando pelo parergon mais do que pela obra estabelecida - o ergon - preferindo a porta secreta ao grande portal?

A resposta está talvez em procurar o que Merleau-Ponty desenvolve em O filósofo e sua sombra, espécie de meditação-homenagem dedicada a Husserl. Antecipando uma leitura derridiana que virá se alojar nos recantos e margens dos textos filosóficos, para aí revelar a estrutura interna e fazer aparecer o impensado, Merleau-Ponty afasta imediatamente do jogo a possibilidade de uma relação frontal com a obra de um pensador: a herança de Husserl estaria, desse modo, talvez menos no que inaugurou do que no que continua a abrir, menos no que produziu, a reflexão acabada, do que na reflexão a ser feita. Assim, o que Husserl transmitiu está tanto em suas zonas luminosas quanto no que permanece na sombra, este impensado de um autor que não é o que lhe falta em relação a outro, mas o que lhe pertence de mais próprio e que, no entanto, não saberia explicar como seu.

Em seguida a Henri Gouhier, que explorava as relações entre a filosofia e sua história, Merleau-Ponty interroga se "podemos colocar em 
uma filosofia as questões que ela mesma não se coloca". Responder esta questão pela negativa, diz Merleau-Ponty, seria "negar a filosofia" (MERLEAU-PONTY 1964, p.249). A Derrida - a quem se criticou tantas vezes por não enfrentar as grandes questões levantadas por um autor e se acantonar nas margens do discurso, no arbitrário de um hápax, de um silêncio ou de um não-dito - Merleau-Ponty deixa por assim dizer um álibi precautivo:

Assim como o mundo percebido só se sustenta pelos reflexos, sombras, níveis, horizontes entre as coisas, que não são as coisas, mas também não são nada (...) também a obra e o pensamento de um filósofo são feitas de certas articulações entre as coisas ditas, aos olhos das quais não há o dilema da interpretação objetiva e do arbitrário, já que não há aqui objetos de pensamento, já que, como a sombra e o reflexo, nós os destruiríamos se os submetêssemos à observação analítica ou a um pensamento isolante, e que não se pode lhes ser fiel ou reencontrá-los senão pensando-os de novo (MERLEAU-PONTY 1960. p.202).

Não é sem dúvida indiferente que nos seus respectivos percursos (que estão longe de serem paralelos), tanto Merleau-Ponty quanto Derrida tenham se inspirado num mesmo autor, a quem a importância conferida à Beilage III da Krisis se acompanha de uma atenção particular ao tema do "impensado": Eugen Fink. É Eugen Fink que, em 1939, um ano após a morte de Husserl, publica a primeira versão de um texto inédito na Revue internationale de philosophie, dando-lhe por título " A questão da origem da geometria como problema histórico-intencional" [Die Frage nach dem Ursprung der Geometrie als intentional-historisches Problem]. Este texto será modificado em seu contexto, a partir de outros manuscritos, por Walter Biemel, em 1954, e se tornará o apêndice III da Krisis, no volume VI da Husserliana (HUSSERL 1939 e HUSSERL 1954). É ainda Fink quem introduzirá Merleau-Ponty ao Nachlass husserliano, na ocasião de sua visita a Louvain, em abril de 193910, o mesmo Fink que já havia sido citado no projeto de pesquisa de 1934, com o artigo de Merleau-Ponty sobre Husserl (MERLEAUPONTY 1989, p.21). A particular insistência de Fink recai sobre a noção husserliana de "Stiftung", que Merleau-Ponty traduz por "instituição".

Mais do que uma operação constituída por um sujeito senhor de suas projeções, a instituição remete acima de tudo a qualquer coisa que se faz, 
preferencialmente ao que se poderia dela fazer, ela contém sempre um lado anônimo, inacessível, uma parte de sombra, já que de cara excede o sujeito individual. Não mais do que o objeto perceptível é constituído pelo sujeito percipiente que faria desfilar sobre o palco de um teatro privado as aparências que manipularia ao seu bel prazer, a fala não pertenceria ao locutor que, no entanto, acredita agir por conta própria. Sem cessar, explica Fink, falamos e cremos saber o que dizemos, e, no entanto, nossas palavras são expedientes que utilizamos porque as herdamos sem que sejamos capazes de restituir-lhes a origem (FINK 1939, p.117-223).

Merleau-Ponty faz eco a essa ideia quando sublinha, na Fenomenologia da Percepção, que quando digo que

"espero desde muito tempo" ou que "alguém morreu", creio saber o que digo. Entretanto, se me interrogo sobre o tempo ou sobre a experiência da morte, que estavam implicados em meu discurso, há apenas obscuridade em meu espírito. É porque eu quis falar sobre a fala, reiterar o ato de expressão que deu um sentido à palavra morte e à palavra tempo, estender o poder sumário que elas me asseguram sobre minha experiência (MERLEAU-PONTY 1945. p.449).

Essa reiteração implica sempre uma re-instituição, uma re-tomada, mas o simples fato de que a retomada seja necessária já indica que o objeto da retomada não havia sido completamente compreendido, que sua apreensão permanece em instância e que ela é infinitamente relançada. Isso significa dizer que a condição de toda ação, de toda fala, de todo pensamento, está em que nem tudo já está feito, nem tudo já está dito, nem tudo está pensado, ou, melhor, que todo ato seja, na sua intencionalidade mesma, acompanhado de um halo de indeterminação que é prévio à sua realização. Assim como só se pode perceber porque tudo não é dado simultaneamente, porque só se percebe por um jogo de perfis ou de Verschattungen, de "ensombramentos" como dizia Husserl, o sensível ganha em relevo, desenvolvendo progressivamente seus aspectos ao fazer outros passar para o segundo plano, assim também só há pensamento onde os conceitos se articulam segundo um princípio semelhante ao que Fink chama de Verschattung do pensamento.

Não podemos superestimar a importância da comunicação feita por Fink em Royaumont, em 1957, a qual tanto Merleau-Ponty e Derrida se 


\section{2}

referem em numerosas passagens. Fink aí desenvolve a ideia de que em todo pensamento há conceitos "operatórios", que só funcionam porque não são tematizados, e que operam tão mais eficazmente quanto mais não acedem ao estatuto de conceitos completos, que se pudesse isolar e submeter à análise:

Isto que num pensamento filosófico é correntemente utilizado, atravessado pelo pensamento [Durchdachte], mas não propriamente pensado [Bedachte], nós o nomeamos: conceitos operatórios. Eles são, para empregar uma metáfora, a sombra de uma filosofia. (FINK 1957 e FINK 1994. p.152)

\section{Os paradoxos da enunciação}

Em sua conferência inaugural no Collège de France, em 1970, intitulada $A$ ordem do discurso, Michel Foucault havia inscrito a fenomenologia merleau-pontyana (apesar de jamais nomeá-la expressamente), numa lista de pensamentos logofóbicos, amedrontados pelo surgimento repentino e não originário de enunciados e supostos a preferir permanecer no horizonte seguro de uma palavra primordial das coisas mesmas (FOUCAULT 1971, p.445). É ainda nesta ótica que podemos ler a teoria derridiana da escrita, presumida a substituir a vida solitária do sujeito pelo "campo anônimo" do escritural. Isso seria esquecer, entretanto, que não somente a reflexão foucaultiana não poderia ser completamente separada de sua inspiração merleau-pontyana (com a evidência do termo emprestado "arqueologia" e um dos capítulos de As palavras e as coisas, que se intitula exatamente "A prosa do mundo"), mas, mais ainda, que a teoria da escrita, segundo Derrida, não é uma alternativa à fenomenologia, mas sobretudo o esforço para colocar em dia os pressupostos inerentes, aqui outra vez na seqüência da iniciativa de Eugen Fink.

A leitura derridiana de Husserl mira, segundo suas próprias palavras, “a axiomática impensada da fenomenologia de Husserl” (DERRIDA 1990a, p. 445), dito de outro modo, o pressuposto linguareiro de seu pensamento, jamais tematizado enquanto tal. Todo o problema é que a fenomenologia se vê obrigada, em seu esforço de explicitação da esfera transcendental, a usar termos que, eles próprios, não podem ser transcendentais, a usar então termos concretos, forjados numa língua empírica, ao 
passo que a enunciação particular compromete o estatuto universal por ela pretendido. Ora, se Derrida fala, a propósito de Husserl, de uma "desatenção ao problema de sua própria enunciação" (Idem, ibidem), ele apenas retoma, por sua conta, a observação de Fink, evocando, para a descrição fenomenológica, um "paradoxo específico" que é aquele da "situação da enunciação": esta última supõe que já se coloque no ponto de vista da redução transcendental, ainda que aquilo que deve permitir aí aceder - a linguagem - não poderia ser transcendental, sob pena de não ser compreendida (FINK 1974, p.173). Toda fala, a partir daí, permanece protética ou ainda incoativa. (Além disso, podemos perguntar: com o que poderia parecer uma linguagem que seria desmanchada de seus trapos provisórios, com o que pareceria, então, uma fala que não tivesse mais nada de empírico...?).

Merleau-Ponty foi sensível a esta problemática desde cedo. Para o primeiro colóquio internacional de fenomenologia que aconteceu em abril de 1951, em Bruxelas, Merleau-Ponty decide enfrentar, em sua conferência, a relação entre a fenomenologia e a questão da linguagem. Considerando que esta questão raramente é tematizada por Husserl, nem por isso ela é menos central, uma vez que a linguagem aí aparece "ao mesmo tempo como um problema especial e como um problema que contém todos os demais, inclusive os da filosofia" (MERLEAU-PONTY 1960, p.116). Pois, se a fenomenologia deve ser mais que um fenomenismo subjetivo, e visa, através da descrição de conteúdos experienciais, a extrair validades gerais, ou seja: um lógos do fenômeno, ela deve se exteriorizar e seus resultados devem poder ser partilhados (no mesmo sentido da Mit-Teilung, de uma partilha comunicante). Assim como não há linguagem privada, não há o antepredicativo de que se poderia falar independentemente de toda predicação; de algum modo, ele é o resultado de um movimento retrógrado da fala que, ao falar, institui o que dela procede. Não há mais pensamento sem corpo, assim como proposição emancipada de suas manifestações empíricas, sustenta Merleau-Ponty, invocando aqui tanto a Lógica formal e transcendental quanto $A$ origem da geometria: a significação não precede sua exteriorização, ela não é o produto de uma interioridade que, em seguida, dela fará parte ao se exprimir a céu aberto; ela antes se institui como a mesma, em todas as operações de concretização, em todas as encarnações concretas, de tal 


\section{4}

modo que "as palavras e toda a fala encarnam [verleiblichen], por assim dizer, a visada [Meinung] nelas mesmas, e a carregam, encarnada nelas [verleiblicht] como sentido."11

Entretanto, se há ponto de ruptura, ela se opera sem dúvida aqui sobre as escolhas semânticas serradas e ambíguas. Pois se o sentido que foi transmitido pela tradição ou pela história deve ser retomado por um sujeito encarnado que deve dele se apropriar para compreendê-lo, esse sentido deve poder permanecer válido independentemente e para além de tal ou tal sujeito encarnado e consequentemente submetido às leis da finitude. Enfim, a possibilidade de encarnação (Verleiblichung) depende da possibilidade de incorporação (Verkörperung), pois apenas o que teria sobrevivido enquanto depósito ou sedimento poderá fazer o objeto de uma retomada que lhe insuflará uma nova vida. É o que Suzanne Bachelard, tradutora de Formale und transzendentale Logik, bem percebeu: "Através dos signos e dos sons, as formações ideais não são somente verleiblicht, mas verkörpert.” (BACHELARD 1957, p.167). Ou, para dizer como Eugen Fink, a idealidade supõe a exterioridade: "Que a filosofia seja então o ser-fora-de-si [Außersichsein] da filosofia - seja exteriorização - não significa, entretanto, uma anomalia fatal", é a "condição de possibilidade para a conservação e a transmissão do pensamento filosófico dentro de uma tradição" (FINK 1994, p.46). Ou ainda, para concluir com Merleau-Ponty: "A existência ideal está fundada sobre o documento" (MERLEAU-PONTY 1960, p.121).

\section{A "falta de existência persistente" e o problema do médium}

Se comparamos as duas leituras de $A$ origem da geometria, não é espantoso que, nesse manuscrito husserliano, Merleau-Ponty e Derrida contornem o mesmo problema central. Todavia, nada destinava ver essa reflexão a respeito das exigências internas de uma "história da geometria", a priori marginal, tornar-se um potente vetor de interpretação do projeto fenomenológico em sua totalidade. Segundo o "princípio dos princípios", nenhum argumento de autoridade é aceitável em fenomenologia, e uma evidência herdada não seria uma evidência, já que, segundo Husserl, apenas "o que se nos oferece na intuição de modo originário" será fonte 
de conhecimento verdadeiro. Neste sentido, o exemplo do Ménon indica como uma lei geométrica como o teorema de Pitágoras permanecerá abstrata, por tanto tempo quanto o escravo nela não tiver verificado, por si mesmo, o caráter intuitivo. Em outras palavras, se as leis geométricas permanecem "válidas" (geltend) por todo tempo, não é sempre, todavia, que são "intuídas" (eingesehen), e é preciso perguntar em quais condições as idealidades podem permanecer in sursis, fora da consciência intuitiva, para poderem, em seguida, nela serem retomadas. Portanto, é exatamente o intuicionismo - que Derrida e Merleau-Ponty sublinham - que conduz Husserl a uma reflexão sobre a história.

Mais exatamente, o intuicionismo é sinônimo de uma dupla finitude: esta do fenômeno, inevitavelmente efêmera e fugaz, e aquela da consciência, que lhe é correlata. Para que alguma coisa apareça, é preciso que outra coisa seja retirada, esquecida e depositada sobre o fundo. Se a temporalização é, portanto, a condição da intuição, ela anuncia também sua ruína, já que o que se dá à intuição sensível se dá em presença, leibhaft, e essa Leibhaftigkeit prorroga também infinitamente a apreensão total, abrindo uma perspectiva interminável de aspectos parciais. Mas essa limitação inerente a todo objeto sensível, inerente a todo objeto "em carne e osso", que faz que de um cubo eu só veja três lados a cada vez, toca também, se bem que de outro modo, os objetos ideais, e essa é a razão pela qual, de certa maneira, a questão da gênese dos objetos ideais coloca à fenomenologia um desafio ainda maior do que o da constituição do objeto sensível. Pois, se no conceito de cubo, todos os lados podem, com efeito, ser pensados de uma só vez, eles não podem intuitivamente ser pensados por todo tempo. Nesse momento Husserl esbarra no problema da "persistência da idealidade", nota Merleau-Ponty (MERLEAU-PONTY 1988, p.69). Es fehlt das verhanrrende Dasein, "falta a existência perdurante", segundo a tradução de Derrida (HUSSERL 1939, p.371).

Se o correlacionismo estrito de Husserl lhe evita a hipóstase idealista, conduzindo toda lei ou ideia à sua manifestação para uma consciência, o correlacionismo pode rapidamente converter-se em relativismo, quando todo em si é dependente do para si, momentâneo e contingente, de uma consciência. Como justificar então que as idealidades remanescentes guardem sua validade, justamente quando não são intuitivas, sem reiterar as antigas clivagens metafísicas? A solução consistirá em corporificar estas 


\section{6}

idealidades sem recorrer ao sujeito encarnado, isto é, em fazê-las sobreviver enquanto fósseis, sedimentos ou depósitos não-vivos. A soma de ângulos de um triângulo formaria ainda sempre $180^{\circ}$, mesmo se disso ninguém tivesse consciência.

Do ponto de vista fenomenológico, é preciso que haja uma historia da geometria, pois era necessário que um dia um "proto-geômetra" tenha tido a intuição do teorema para provar sua realidade (pouco importa se seu nome era Pitágoras). Mas é esta mesma historicidade que, para permitir outras descobertas e intuições, provoca o esquecimento. A intuição passada sobrevive na escrita que consigna o sentido, e é ainda esse suporte material que permitirá sua reativação, assim como, no Ménon, o escravo reativará a intuição do teorema através dos esquemas gráficos que Sócrates traça na areia depois de tê-la alisado. Toda descoberta supõe o apagamento recíproco de outra coisa, e, por conseqüência, toda "filosofia do descobrimento" implica, por sua vez, uma "filosofia do recobrimento"12. Ou, como diz Merleau-Ponty ao citar o Husserl da Krisis, há, sempre simultaneamente, o "Entdeckung e Verdeckung da Razão" (MERLEAU-PONTY 1996, p.75).

Ora, a instituição de uma idealidade não se faz segundo esse encadeamento fundado que caracteriza a percepção e seus descobrimentos-recobrimentos sucessivos no perfilamento dos objetos. Eis porque todas as teorias da gênese empírica permanecem insuficientes, pois a instituição advém invariavelmente de modo repentino, representando um salto qualitativo inexplicável enquanto tal, uma epi-gênese que remonta a um instantâneo - um exaiphnes - de que apenas podemos explicar posteriormente o advento. Ou, para dizer conforme um exemplo de MerleauPonty no curso sobre a dialética: constata-se uma calvície, jamais seu nascimento (MERLEAU-PONTY 1955).

Vale a mesma coisa para toda descoberta das leis da natureza: descobrimos apenas post festum o que se apresenta ao modo de um particípio passado, isto é, sempre como havendo sido em vigor. Hegel dizia que a essência (Wesen) é o que terá sempre sido (gewesen) ${ }^{13}$. Trata-se de uma espécie de futuro anterior, que permanece cego, entretanto, àquilo em direção ao qual se dirige, de modo tateante. A intuição das idealidades é assim raramente contínua, pois procede sobretudo por intermitências, apoiando-se sobre pausas que são ao mesmo tempo interrupções e 
momentos fecundos, para dar novos saltos. Husserl, evocando a comunidade de pesquisadores, fala de inevitáveis "pausas profissionais" e de "pausas de sono", na sequência das quais o pesquisador não recomeça do zero, mas se apóia em suas notas, responsáveis por restituir aquilo que a consciência terá esquecido (HUSSERL 1954, p.373; HUSSERL 1993, p.189). Ou, nos termos de Husserl, no período onde um inventor não está acordado ou ainda não se encontra mais em vida, é a escrita que "torna possível as comunicações sem alocução pessoal, mediada ou imediata", tornando-se "comunicação sobre o modo virtual" (virtuell gewordene Mitteilung) (HUSSERL 1939, p.371; HUSSERL 1974, p.186).

Sem embargo, a escrita é mais do que uma prótese memorial. De certa maneira, ela precede a intuição viva, dirá Merleau-Ponty, pois longe de ser apenas uma reatualização de um inatual, ela é sobretudo a ativação de um passado que jamais foi presente, o traço de uma intuição anônima de que jamais algum indivíduo teve experiência:"a escrita funda a preexistência de idealidades que ninguém experienciou e concebeu em evidência” (MERLEAU-PONTY 1988, p.71). Merleau-Ponty parece quase antecipar, aqui, a ideia que Derrida formulará mais tarde, referindo-se a Jean Hippolyte, onde a escrita é concebida como "campo transcendental sem sujeito". O que não "foi vivido em evidência por ninguém" não tem, assim, existência atual ou inatual, mas "virtual" (Idem, p.28). Paradoxo da escrita que é acessório, sim, mas no sentido de um duplo movimento temporal que atravessa o horizonte da fenomenologia husserliana: essa intuição que não é mais e aquela que não é ainda, horizonte último da adequação. A escrita supre, então, na ausência, na falta de uma intuição, ao mesmo tempo isso que permite a transmissão de uma certa verdade e aquilo que nela condiciona a descoberta. Já Husserl nota que num certo sentido a escrita precede o estabelecimento da geometria: "É claro que o método de produção de idealidades originárias, a partir de dados précientíficos do mundo da cultura, deve ter sido anotado e fixado [niedergeschrieben und fixiert] em proposições estáveis antes da existência da geometria; em seguida, é claro que o poder de fazer passar estas proposições de sua vaga compreensão lingüística à clareza da reativação de um sentido evidente deve ser transmitido e transmissível continuamente em sua forma própria." (HUSSERL 1939, p.375; HUSSERL 1974, p.194). 
O objeto ideal não tem, portanto, nada de abstrato ou de transcendente. Mais do que o objeto sensível, ele se mostra tributário de um médium - desempenhado pela escrita, ou, de modo mais geral, por toda fixação empírica - responsável por lhe assegurar a persistência intuitiva que lhe faltava. O objeto ideal existe através deste médium: é por este último que ele acontece e se perpetua. Pois, se ele é válido para todo o tempo (allzeitlich), não é perpétuo (überzeitlich), e sua falta de evidência chama infatigavelmente o que lhe remedia. Eis porque Derrida perde o sentido da palavra "Immerfort-Sein", ao traduzi-la por "ser de perpetuidade" (Idem, ibidem ), pois só o que não é eterno pode acontecer de novo e de novo, só o que não é perpétuo pode se repetir. É idealmente válido, diz Husserl, o que é "immerfort”, a um só tempo o que se mantém através das diferentes variações, mas também reivindica incessantemente ser reiterado. Immerfort: por todo sempre, infinitamente prorrogado, constantemente relançado, pois que jamais inteiramente aí. Assim, o Immerfort-Sein se opõe ao Da-sein, porque excede sua finitude, mas também porque a presença corporal lhe falta; o Immerfort-Sein é um FortSein, um "ser-longe", afastado da origem, jamais integralmente em presença, horizonte aberto sobre o que Merleau-Ponty nomeia de "mediação infinita" (MERLEAU-PONTY 2001. p.402).

\section{Da origem da diferença à diferenciação da origem}

Tentemos nesse momento resumir o rápido percurso que visava mostrar o inextricável entrelaçamento entre dois pensadores, a priori divergentes, Merleau-Ponty e Derrida, quanto ao problema da mediação. Em suas reconstituições autobiográficas, Derrida lembra mais de uma vez a importância que representa para ele, na superação de uma filosofia da imanência do vivido, o livro do fenomenólogo vietnamita Tran Duc Thao, Fenomenologia e materialismo dialético, cuja leitura lhe havia sido aconselhada por Foucault ${ }^{14}$. Derrida compreende que o propósito do livro não é tanto a tentativa de síntese entre fenomenologia e marxismo histórico (que deveria necessariamente permanecer artificial), mas uma leitura mais profunda de Husserl, a fim de fazer aparecer as tensões inerentes ao intuicionismo, que conduzem a uma reavaliação da história. 
Numa interpretação muito particular do último Husserl, que pôde analisar por ocasião de dois períodos de estudos nos Arquivos Husserl, em janeiro e abril de 1944 (COURTINE 1989), Tran Duc Thao reconhece que a mediação é a pedra de toque do husserlianismo. A idealidade requer um médium para se instaurar, mas essa instauração mediata compromete, logo de cara, o télos de uma apreensão que seja, um só tempo, adequada e originária - pois o médium, se verdadeiramente se constitui um prelúdio à intuição ideal, é igualmente fonte da crise das ciências (THAO 1951). Derrida reconheceu sua dívida para com Tran Duc Thao na elaboração de sua teoria da escrita, mas é preciso acrescentar que isso é também uma maneira de reconhecer sua dívida em relação a Merleau-Ponty. (É ainda Sartre quem lembra tal vínculo, no momento da morte de MerleauPonty: "Sem Merleau-Ponty, acreditaríamos que Tran Duc Thao teria escrito sua tese conectando Husserl e Marx? (SARTRE 1964. p.243). Um fio a mais nessa história intelectual que nos deixa o desafio de reconstituir um dia a trama inteira.

Por ora, limitemo-nos a constatar o estranho retorno, o quiasma, por assim dizer, entre Merleau-Ponty e Derrida, que terminou por obscurecer a linha que os dividia. Pôde-se afirmar, com razão, que o pensamento derridiano da diferença se ancorava em sua leitura de Husserl, onde é antecipado pela primeira vez (LAWLOR 2000, p.205). Paradoxalmente, para introduzir o caráter diferente da escrita, Derrida é obrigado a reconduzi-lo ao Leib. Não é enquanto escrita que ela não é um simples corpo inerte (Körper), mas enquanto inerva o sentido que transporta e expõe de maneira carnal (como Leib), que a escrita ultrapassa a imanência do sujeito individual (DERRIDA 1974, p.97).

Inversamente, no calor do Curso sobre a dialética, Merleau-Ponty parece aprofundar, com $A$ origem da geometria, uma problemática que ultrapassa o tema do Leib vivo, fundamento da Fenomenologia da Percepção, para avançar na direção do que ele também chama de "aparelhos de conhecimento" (MERLEAU-PONTY 2003, p.98). As idéias são "levadas ao mundo por seus instrumentos de expressão, os livros, os museus, as partituras, os escritos" (MERLEAU-PONTY 2000, p.110). Compreender como os sujeitos, "que não vivem ao mesmo tempo", podem participar das mesmas idéias, não é instaurar uma nova doutrina da methexis platônica, mas, ao contrário, descrever como as idealidades "incorporam-se nos instrumentos 
culturais" (Idem, p.111). O aparecer jamais é imediato, mas inevitavelmente modulado, articulado e aparelhado por mídias que também são aparelhos do aparecer. Eles permitem a instauração reiterada das idealidades, mas nelas inflectindo também os contornos, ao conferir-lhes novos acentos. Toda instituição de sentido (Sinngebung) implica Sinnverschiebungen, deslocamentos do sentido que se intensificam até se tornarem "transgressões intencionais" (MERLEAU-PONTY 1996, p.83). Derrida formalizou essa intuição: toda iteração é ao mesmo tempo repetição e diferença, conforme a raiz da palavra (iterum, do sânscrito itará, "outro”), que faz de toda iteração uma alteração (DERRIDA 1972, p.375). Mais no fim de sua vida, sabe-se, Merleau-Ponty trabalhava no projeto de um livro que deveria se chamar $A$ origem da verdade. Como não ver aí o efeito imediato de uma interrogação sobre a gênese das idealidades?

Ora, o fato mais perturbador é, sem dúvida, que duas idéias “originalmente" derridianas se encontrem formuladas por Merleau-Ponty. A letra que, por sua materialização e por tornar-se pública, subtrai-se da autoridade de seu produtor e instaura sua "destinação errante", não pode ser conduzida a nenhuma origem, a nenhum auctor: a letra é transmissão (Tradierung), tradição que, enquanto tal, é "traço" anônimo: "Eu descubro uma mensagem - e sem saber de quem." (MERLEAU-PONTY 1988, p.33). Como todo médium, este último só é operante, em sua operação de transferência, fazendo desaparecer o que lhe tornou possível, e o canteiro que se terá aberto só pode ser percorrido novamente se o que o abria tiver sido retirado. Se a operação instituinte (o Vollzug) repousa constitutivamente sobre a possibilidade de sua retomada (Nachvollzug), ela só permanecerá operante durante o tempo em que for instância operante - enquanto médium. Ela não se cristaliza em objeto. A discussão em torno do discurso como figura operante da fala filosófica, de que falam sucessivamente Fink, Merleau-Ponty, Foucault e Derrida, terá colocado de uma vez por todas um problema mais vasto: o do caráter operante de todo médium de fenomenalização, que só opera enquanto não é tematizado. O esquecimento da origem, desde então, é menos o resultado de uma história destinal do ser, que se poderia esperar inverter, do que o esquecimento constitutivo e intransponível do médium. A Stiftung é mascarada por seus próprios resultados, diz também Merleau-Ponty, uma vez que ela supõe sua temporalização em um médium empírico, mas essa 
temporalização contemporiza também sua instituição definitiva, empurrando um pouco mais longe o horizonte de seu fechamento. A operação de Stiftung "ignora-se", diz Merleau-Ponty, pois que procede ela mesma do mundo do Lebenswelt.

E a operação primeira do mundo histórico-sensível - Merleau-Ponty antecipa aqui outra ideia de Derrida - consiste, se bem compreendida, em diferir:"“a operação de Stiftung [...] vem do Lebenswelt, que diferia estas operações” (MERLEAU-PONTY 1988, p.76). Com a leitura merleaupontyana de $A$ origem da geometria, a diferença se antecipa, dá-se outra origem ou descobre-se sobretudo como aquilo que, infinitamente, remete à arqueologia das origens. E, no entanto, como gostava de dizer Husserl: ainda há, no coração deste fracasso, "um triunfo" (ein Gelingen in diesem Versagen) (HUSSERL 1954, p.510. HUSSERL 1993, p.565).

1 DAMISH 1993, p.105: "Assim como a introdução de Jacques Derrida a A origem da geometria, recorro aqui a um curso inédito professado por Maurice Merleau-Ponty no Collège de France, em 1959-1960, sob o título 'Husserl além da fenomenologia', o último que me foi concedido assistir e em que as notas que conservei foram feitas para persuadir-me de uma dívida, imensa, contratada com o seu autor."

2 BARING 2011. Em particular cf. o capítulo I.2: “Derrida's christian existencialism”.pp.4881.

3 Emprestamos aqui a expressão "momento filosófico" de Frederic Worms. Cf. igualmente WORMS 2011.

4 MALABOU 1999, p.284: “1954: Primeira 'passagem de fronteira', primeiro 'país estrangeiro'. Então como aluno da École Normale Supérieure (1952-1956), breve período de estudos em Louvain para consultar os Arquivos Husserl."

5 Idem, ibidem.

6 DERRIDA 1954. Outras notas consagradas a Piaget estão depositadas em Irvine, notadamente sobre os livros Psicologia da inteligência e O julgamento moral na criança. Cf. BARING 2011, p.117.

7 Entrevistas radiofônicas com Catherine Paoletti, 1998. DERRIDA 2003, p.21.

8 Cf. as indicações de Alexandre Métraux em MÉTRAUX 1973, p.21.

9 Cf. Comunicação pessoal de Derrida, em 1997. MORAN 2000. p.438.

10 Cf. a narrativa de Van Breda em VAN BREDA1962. 
11 HUSSERL 1929, p.20. A tradução é retomada e traduzida por Merleau-Ponty em MERLEAU-PONTY 1969, p.44.

12 DERRIDA 1954 citado por BARING 2011, p.117.

13 Cf. a referência a essa frase da Ciência da lógica em MERLEAU-PONTY 2003.p.98.

14 Derrida segundo uma entrevista com Dominique Janicaud. JANICAUD 2001, p.402.

\section{Referências bibliográficas}

BACHELARD, Suzanne. 1957. « La logique de Husserl ». In: Essais philosophiques.

BALIBAR, Etienne. 2002. "Histoire de la vérité " In: BADIOU, Alain. Penser le multiple. Dirige par Charles Ramond. Paris: L'Harmattan.

BARING, Edward. 2011. The Young Derrida and french philosophy. 19451968. Cambridge: Cambridge University Press.

COURTINE, Jean-Francois. 1989. "Fondation et proto-fondation des Archives Husserl à Paris. » In: Husserl. Org. Eliane Escoubas e Marc Richir. Grenoble: Millon.

DAMISH, Hubert. 1993. L'origine de la géométrie. Paris: Flammarion.

DERRIDA, Jacques. 1954. Psicologia e objeto. Aula não-datada ministrada na École Normale Supérieure por volta de 1954/55. Arquivos Derrida, Irvine (Califórnia).

DERRIDA, Jacques. 1972. "Signature événement contexto » In: Marges de la philosophie. Paris: Minuit.

DERRIDA, Jacques. 1974. Introduction à l'Origine de la géométrie. Paris : PUF.

DERRIDA, Jacques. 1990a. «Ponctuations: le temps de la thèse. » In : $\mathrm{Du}$ droit à la philosophie.

DERRIDA, Jacques. 1990b. Le problème de la gênese dans la philosophie de Husserl. Paris: PUF. 
DERRIDA, Jacques. 2003. Sur parole. Instantanés philosophiques. Paris: L'Aube.

ERIBON, Didier. 1989. Michel Foucault. 1926-1984. Paris: Flammarion. FERRARIS, Maurizio. 1997. "Entretien avec Mauricio Ferraris de 1994 » In : Il gusto Del segreto. Roma: Laterza.

FINK, Eugen. 1939. «Das Problem der Phänomenologie. » In : Revue Internationale de Philosophie 1, no.2.

FINK, Eugen. 1957. « Operative begriffe in Husserls

Phänomenologie». In: Zeitschrift für philosophische Forschung 11.

FINK, Eugen. 1974. «La philosophie phénoménologique d'Edmund Husserl face à la critique contemporaine. »In: De la phénoménologie. Trad. Didier Franck. Paris: Minuit.

FINK, Eugen. 1994. "Les concepts opératoires dans la phénoménologie de Husserl. "In:.Proximité et distance. Essais et conférences phénoménologiques. Traduit par Jean Kessler. Grenoble: Million. FOUCAULT, Michel. 1971. L'ordre du discours. Paris: Gallimard.

FOUCAULT, Michel. 1985. La vie: l'expérience et la science. In : Revue de Métaphysique et de morale, 1985, janvier-mars.

FOUCAULT, Michel. 2001a. " Foucault répond à Sartre - Entretien avec J.-P. Elkabbach, 1968. In : Dits et écrits, vol.1 - 1954-1975. Paris: Gallimard.

FOUCAULT, Michel. 2001b. Dits et écrits - vol II. Paris: Gallimard.

HUSSERL, Edmund. 1929. Formale und transzendentale logik. Halle: Niemeyer.

HUSSERL, Edmund. 1939. Die Frage nach dem Ursprung der Geometrie als intentional-historisches Problem. Ed. Eugen Fink, Revue Internationale de Philosophie 1, no.2 (1939).

HUSSERL, Edmund. 1954. Walter Biemel. Husserliana vol VI. La Haye: Nijhoff. 


\section{4}

HUSSERL, Edmund. 1974. L'origine de la géométrie. Paris : PUF.

HUSSERL, Edmund. 1993. La crise des sciences européennes et la phénoménologie transcendantale. Paris : Gallimard.

JANICAUD, Dominique. 2001. Heidegger en France. vol 2. Paris: Albin Michel.

LAWLOR, Leonard. 2000. "L'héritage de l'Origine de la géométrie: Les limites de la phénoménologie chez Merleau-Ponty et Derrida.» In: Chiasmi Intenrational 2. Paris:Vrin.

MALABOU, Catherine. 1999. La contre-allée. Paris: Quinzaine littéraireVuitton.

MERLEAU-PONTY, Maurice. 1945. Phénoménologie de la perception. Paris: Gallimard.

MERLEAU-PONTY, Maurice. 1955. Notes préparatoires pour le Cous sur la dialectique au College de France. Cours de lundi et du jeudi - 1955/56. Transcription de David Belot et Jean-Philippe Narboux. Archives Merleau-Ponty, BNF, f.161v.

MERLEAU-PONTY, Maurice. 1964. Le visible et l'invisible. Paris: Gallimard.

MERLEAU-PONTY, Maurice. 1960. Le philosophe et son ombre. In: Signes. Paris: Gallimard.

MERLEAU-PONTY, Maurice. 1988. Notes de cours sur L'origine de la géometrie de Husserl, suivi de Recherches sur la phénoménologie de MerleauPonty. Org. Renaud Barbaras. Paris: PUF.

MERLEAU-PONTY, Maurice. 1989. Le primat de la perception et ses conséquences philosophiques. Paris: Cynara.

MERLEAU-PONTY, Maurice. 1996. Notes de cours au Collège de France 1959-1961. Paris: Gallimard.

MERLEAU-PONTY, Maurice. 2001. Les sciences de l'homme et la phénoménologie. In: Psychologie et pédagogie de l'enfant. Lagrasse:Verdier. 
MERLEAU-PONTY, Maurice. 2003. L'institution - La passivité. Paris: Belin.

MÉTRAUX, A. 1973. Maurice Merleau-Ponty, Vorlesungen I. Ed. A.

Métraux. Berlin: De Gruyter.

MORAN, Dermot. 2000. Introduction to phenomenology. Londres:

Routledge.

VAN BREDA. 1962. "Maurice Merleau-Ponty et les Archives-Husserl de Louvain ". In : Revue de Métaphysique et de Morale. 67e anée, 1962.

SARTRE, Jean-Paul. 1964. "Merleau-Ponty » In: Situações IV. Paris: Gallimard.

THÁO, Trân Dúc. 1951. Phénoménologie et matérialisme dialectique. Paris:

Minh-Tanh. [1971. Réed. Paris: Gordon e Breach].

WORMS, Frederic. 2011. Le moment philosophique des années 1960 sob a direção de Patrice Maniglier. Paris: PUF. 